\title{
Oswaldo Cruz e a lei de saúde pública na França
}

\author{
Oswaldo Cruz and France's \\ public health law
}

\author{
Renato da Gama-Rosa Costa \\ Arquiteto e urbanista do \\ Departamento de Patrimônio \\ Histórico, COC/Fiocruz \\ Av. Brasil 4365 - Prédio do Relógio \\ 21040-900 - Rio de Janeiro - RJ \\ Brasil \\ rgrc@coc.fiocruz.br.
}

\section{Gisele Sanglard}

Historiadora, pesquisadora visitante da Casa de Oswaldo Cruz/Fiocruz

Rua Barão da Torre, 481/302. Ipanema

22411-003 - Rio de Janeiro - RJ

Brasil

sanglard@coc.fiocruz.br
COSTA, R. da G.-R.; SANGLARD; G.: Oswaldo Cruz e a Lei de Saúde Pública na França.

História, Ciências, Saúde - Manguinhos, v. 13, n. 2, p. 493-507, abr.-jun. 2006.

Pretendemos, através deste trabalho, apresentar a lei francesa de 15 de fevereiro de 1902, relativa à proteção da saúde pública, que se tornou a base do controle da salubridade de moradias, com reflexos no cotidiano das cidades. Acreditamos que, ao mesmo tempo em que participa da gênese das políticas públicas urbanas e que representa o coroamento de um amadurecimento do pensamento higienista francês, essa lei, tendo em vista alguns aspectos próximos, pode ter servido de modelo para o Decreto no 5.156 , que regulamentou os serviços sanitários na gestão de Oswaldo Cruz à frente da Diretoria Geral de Saúde Pública do Distrito Federal, nos primeiros anos do século XX no Rio de Janeiro.

PALAVRAS-CHAVE: saúde pública; políticas urbanas; legislação; França-Brasil.

COSTA, R. da G.-R.; SANGLARD; G.: Oswaldo Cruz and France's public health law.

História, Ciências, Saúde - Manguinhos, v. 13, n. 2, p. 493-507, Apr.-June 2006.

The article discusses the French law on public health protection (February 15, 1902) that formed the foundation for the control of residential salubrity and thus made itself felt in the daily lives of those living in the city. As part of the genesis of urban public policy, the law represents the ultimate maturation of French hygienist thought. In light of certain similarities, it may have served as a model for Brazilian Decree no. 5.156, which regulated sanitation services under Oswaldo Cruz's term as Director-General of Public Health for the Federal District (Rio de Janeiro) at the dawn of the twentieth century. KEYWORDS: public health; urban policies; law; France-Brazil. 
* Este artigo foi desenvolvido a partir de pesquisas realizadas durante $o$ estágio de doutoramento em Paris de ambos os autores, financiados pelas agências de fomento $\mathrm{CNPq}$ e Capes, entre novembro de 2003 e agosto de 2004 .
$\mathrm{O}$ objetivo deste trabalho é apresentar a lei francesa de 1902, relativa à proteção da saúde pública, que se tornou a base das políticas públicas de controle da salubridade de moradias, com reflexos no cotidiano das cidades. O deputado Jules Siegfried ${ }^{1}$ esteve à frente da elaboração e da aplicação dessa lei, que receberia seu nome em reconhecimento por seu empenho e dedicação. Acreditamos que, ao mesmo tempo em que representa o coroamento de um amadurecimento do pensamento higienista francês, essa lei, tendo em vista alguns aspectos próximos, pode ter servido de modelo para o decreto $\mathrm{n}^{-}$5.156, que regulamentou os serviços sanitários na gestão de Oswaldo Cruz à frente da Diretoria Geral de Saúde Pública do Distrito Federal (DGSP) e durante as reformas urbanas empreendidas na Capital brasileira nos primeiros anos do século XX. ${ }^{2}$

Essa lei foi o resultado de uma série de leis e projetos propostos na última década do século XIX, entre as quais a lei de 1893 que instituiu a assistência gratuita e a primeira Lei Segfried, de 1894, sobre as habitations à bon marché. A lei de 1902 entrou em vigor um ano depois de sua promulgação - era o tempo para que as comunas e departamentos se adequassem às novas diretrizes sanitárias. Em março de 1904 é promulgado no Rio de Janeiro o Decreto $n^{\circ} 5156$, que dava novo regulamento aos serviços sanitários a cargo da União. Esse decreto vai permitir que Oswaldo Cruz intervenha na cidade do Rio de Janeiro, pondo em prática a reforma sanitária que, juntamente com a reforma urbana, iria 'modernizar' e 'civilizar' a Capital Federal.

\section{A Lei Siegfried}

O século XIX pode ser considerado como o período do higienismo na França. O controle de epidemias e as ações de saúde pública em geral estavam baseados, desde o século anterior, no controle da pobreza. Se no século XVIII se concebia a higiene como um atributo moral, a modernidade dos séculos XIX e XX lhe daria uma dimensão social e política. No final do século XIX, após as descobertas de Pasteur, verificou-se uma maior atuação política, podendo mesmo falar-se no lobby médico na Assembléia francesa. Lobby esse formado pelos médicos-deputados, ${ }^{3}$ que buscaram criar leis aplicando os conceitos de higiene defendidos por eles.

É nesse período que surge o "pausteurianismo preventivo", que pode ser percebido em dois caminhos diferentes que levam, ambos, ao controle social: de um lado a medicina, a nova via de controle do pobre; de outro o urbanismo, ciência que se está configurando, atuando nas questões das moradias e das cidades salubres. Um bom exemplo são as habitations à bon marché (HBM) construídas em Paris a partir da lei de 1894, e baseadas em preceitos higiênicos rígidos, nos quais o controle do pobre passava também pela moradia salubre. 
A aplicabilidade das leis de 1890 esbarrou em vários pontos, fossem eles limites técnicos, fossem obstáculos corporativos ou mesmo sociais. Foi preciso esperar ainda uma década para o surgimento de uma nova lei que viesse complementá-la.

Esse papel caberia à lei de 1902, que é considerada a primeira Lei Federal Francesa de Proteção à Saúde Pública. Essa lei estabelecia regras uniformes de higiene para o conjunto do país, e pela primeira vez autorizava os funcionários públicos a inspecionar as habitações privadas para verificar sua salubridade. A partir dela a saúde pública se tornou, finalmente, e para a satisfação de inúmeros reformadores sociais e higienistas franceses, uma prioridade nacional, apesar da forte reação que provocou em razão da interferência nos direitos pétreos da propriedade privada (Horne, 2004).

Olivier Faure assim a resume:

A lei de 15 de fevereiro de 1902 referente à proteção da saúde pública tem um alcance mais geral visto que ela está endereçada a todos e estende a noção de obrigação aos prefeitos, aos médicos e aos poderes públicos... ela obriga os prefeitos a agirem concretamente na luta contra as doenças transmissíveis. Cada comuna francesa deverá, doravante, ter um regulamento sanitário que preveja, entre outras, uma série de precauções que visam isolar, transportar os doentes acometidos por uma infecção contagiosa e evitar que o mal se propague na comuna. À luz de experiências passadas, a lei torna também obrigatória a desinfecção e a vacinação... Para conferir uma realidade consistente a todas essas prescrições, a lei obriga todas as aglomerações de mais de 20000 habitantes a ter um centro de higiene nos moldes dos já existentes. Para as comunas menores, a responsabilidade recai sobre os departamentos encarregados de organizar o serviço de higiene pública com a ajuda de um conselho de higiene composto por dez ou quinze membros, e de comissões sanitárias locais mais numerosas que os antigos conselhos de bairros.

O financiamento de todas essas medidas será, então, assegurado pela associação entre as comunas, os departamentos e o Estado, segundo uma proporcionalidade das riquezas de cada umas das coletividades locais. Com essa lei, abre-se também um novo campo de regulamentação, que define normas para os aparelhos de desinfecção, as declarações da doença, estabelece regras para a produção da vacina antivariólica e dos soros, cuja prática é intensamente encorajada (Faure, 1993, p. 247-8)

O sucesso dessa lei traria outras implicações para a vida cotidiana das cidades francesas, como no incentivo à criação da Seção de Higiene Urbana e Rural do Museu Social ${ }^{4}$ em 1908. À frente dela, o mesmo Jules Siegfried. Segundo Janet Horne (2004), a criação desse organismo ocorreu dentro de um contexto que reunia a preocupação com a saúde pública e com certo preservacionismo, este último 
orientado pela proteção aos espaços verdes e à recomendação de uma planificação urbana. Esta teria, por sua vez, a função de ajudar a eliminar os problemas da saúde pública, inevitáveis se a expansão das cidades fosse feita de forma caótica e sem regras. A França seria, assim, como se sabe, o primeiro país a criar um órgão diretamente encarregado das questões do urbanismo enquanto ciência, gestado a partir da Seção de Higiene.

De fato, a partir da lei de 1902, que trazia implicações sobre a regulamentação da construção, higienistas e simpatizantes de uma intervenção pública passariam a denunciar largamente a negligência de alguns poderes locais quanto à aplicação de seus artigos, e reclamariam a criação de uma administração central, a fim de fazer cumpri-la: "As mesmas fraquezas e os mesmos remédios seriam, em conseqüência, sentidos e exigidos para os planos de urbanismo" (Gaudin, 1985, p. 16).

\section{A reforma dos serviços sanitários no Brasil e a Lei Siegfried}

O advento da República no Brasil teve como uma de suas características o pacto federativo que previa, entre outras coisas, a descentralização das ações de saúde, ficando o governo federal restrito ao Distrito Federal. Percebe-se, então, a primeira diferença entre ambos os regulamentos: enquanto a lei francesa previa ação em todas as comunas e departamentos da França continental e do ultramar, o decreto brasileiro restringia suas ações ao Rio de Janeiro. A segunda diferença diz respeito à sua extensão. A Lei Siegfried se restringe à intervenção nas habitações, ao passo que a brasileira abrange estabelecimentos comerciais e industriais, fábricas, oficinas e congêneres.

Outro ponto a salientar refere-se à administração sanitária: na França coube ao Préfet de Police (chefe de polícia) e à sua equipe o controle e a gestão das medidas sanitárias postas em vigor, ao passo que no Rio de Janeiro esse papel coube à DGSP, na figura de seu diretor, Oswaldo Cruz. Se o Préfet de Police tinha poderes de polícia sanitária e abrangia uma área de atuação maior do que a cidade, Oswaldo Cruz, diretor com plenos poderes, estava restrito à circunscrição da capital.

A composição das equipes de cada administração apresenta igualmente um diferencial. A equipe do Préfet de Police era assistida pelo conselho de higiene e de salubridade, que se compunha, além do próprio prefeito, como presidente do conselho, de diversos membros, entre os quais, 15 estavam diretamente ligados às suas profissões: médicos, militares, inspetores sanitários, engenheiros e arquitetos, entre outros. Na equipe carioca constavam inspetores sanitários, de isolamento e de desinfecção, delegados de saúde, demografista, chefe de laboratório e diretores de distrito e dos hospi- 
tais, além de médicos, farmacêuticos e diversos funcionários administrativos. A função do arquiteto, cuja regulamentação profissional só ocorreria na década de 1930, seria assumida pelos engenheirossanitários, capitaneados pelo próprio prefeito do Rio, Pereira Passos.

Vale a pena ressaltar que essa 'Polícia Sanitária' posta em prática pelo Regulamento é percebida nas medidas profiláticas contra a varíola e também contra a febre amarela, consideradas como grandes flagelos dos primeiros anos da República, e teve como principais características a repartição da cidade em dez distritos sanitários. A vacinação em massa foi acompanhada pela realização das brigadas mata-mosquito, que percorriam as ruas buscando destruir os focos de suas larvas - as águas estagnadas. As equipes entravam nas residências, com plenos poderes para aplicar a vacina aos moradores e enxofre e píretro nos ambientes insalubres onde havia sido detectada a presença do mosquito transmissor (Benchimol, 2001, p. 41; Chalhoub, 2004, p. 60).

Por fim, o artigo $6^{0}$ da Lei Siegfried regulamentava a obrigatoriedade da vacinação no curso do primeiro ano de vida e a revacinação aos 11 e aos 21 anos. No Brasil, a lei de novembro de 1904, ao tornar a vacinação obrigatória para todos os habitantes, transformou "a cidade em uma praça de guerra" (Chalhoub, 2004, p. 97), no evento que ficou conhecido como "A Revolta da Vacina".

\section{NOTAS}

1 Jules Siegfried nasceu em 1837, na Alsácia, e foi comerciante, empresário de tecidos e político (deputado, senador, ministro do Comércio). Siegfried chegou a Paris em 1887 e um dos seus primeiros atos como deputado foi o projeto de lei da criação do Ministério da Saúde Pública.

$2 \mathrm{Na}$ biblioteca particular de Oswaldo Cruz (DAD/COC/Fiocruz) encontra-se o livro Vaccination et revaccinations obligatoires: em application de la loi sur la protection de la Santé Publique, de G. Borne, lançado pela C. Naud Éditeur, Paris, 1902, evidenciando o conhecimento da lei pelo cientista. Resta a dúvida se durante seu estágio no Instituto Pasteur (1897-1899) Oswaldo Cruz também teria tido contato com as discussões em torno de sua promulgação. G. Borne, segundo a introdução do livro, foi relator na Câmara dos Deputados durante a promulgação da lei, atuando em nome da Comissão de Higiene.

${ }^{3}$ Entre os médicos-deputados citados como defensores do higienismo na Assembléia Nacional Francesa estão Liouville, Langlet e Cornil, sem contar o representante dos filantropos, Jules Siegfried (Faure, 1993, p. 244).

${ }^{4}$ No início do século XX, as reformas urbanas eram ainda campo de atuação de médicos. Com a lei de 1902, reconhecia-se "um vasto campo de intervenção onde se poderiam combinar, dentro do quadro de regulamentos municipais de higiene, critérios médicos com normas topográficas e volumétricas de construção" (Gaudin, 1985, p. 79). É neste contexto que se deu a criação do Museu Social (1894), contribuindo para difundir um conceito mais amplo de higiene, atuando tanto nas normas sanitárias obrigatórias das habitações individuais, quanto na intervenção fundiária urbana e na planificação espacial, antes mesmo da difusão do termo urbanismo (ibidem, p. 79). A composição dos integrantes do Museu Social revelava a multidisciplinaridade de profissionais. Além de médicos, como Émile Roux, havia engenheiros, arquitetos - como Donat-Alfred Agache, que teria atuação primordial na gênese do urbanismo científico no Brasil - e políticos - como Léon Bourgeois e Paul Strauss, que trabalharam pela instrução e pela Assistência Pública na França, militando tanto na Assembléia como em periódicos, tais como o Journal d'Hygiène, a Revue d'Hygiène e a Revue Philantropique, entre outros. 


\title{
A Lei de 15 de fevereiro de $1902^{5}$
}

\section{TÍTULO PRIMEIRO - DAS MEDIDAS SANITÁRIAS GERAIS}

\author{
CAPÍTULO PRIMEIRO - \\ Medidas sanitárias gerais
}

Art. $1^{o}$. Em toda comuna, o prefeito é obrigado a determinar, a fim de proteger a saúde pública, após concordância do conselho municipal e sob forma de editos municipais, dentro dos regulamentos sanitários: 1) as precauções a serem tomadas, na execução do artigo 97 da lei de 5 de abril de 1884, para prevenir ou cessar as doenças transmissíveis, objetivadas no artigo 4 da presente lei, especialmente as medidas de desinfecção ou mesmo de destruição dos objetos de uso dos doentes ou que tenham sido utilizados por eles, e em geral quaisquer objetos que possam eles mesmos servir de veículo de contágio; 2) as prescrições destinadas a assegurar a salubridade das residências e de seus dependentes, as vias privadas, fechadas ou não em suas extremidades, os alojamentos alugados nas mansardas e outras aglomerações qualquer que seja a natureza, notadamente as prescrições relativas ao abastecimento de água potável ou ao escoamento das matérias servidas.

Art. 2. Os regulamentos sanitários comunais não são obstáculo aos direitos conferidos aos prefeitos pelo artigo 99 da lei de 3 de abril de 1884. Eles são aprovados pelo prefeito, após concordância do conselho departamental de higiene. Se, no prazo de um ano a partir da promulgação da presente lei, uma comuna não tem regulamento sanitário, lhe será imposto um, oficial, por um edito do prefeito, com aval do conselho departamental. No caso onde várias comunas tiverem feito conhecer o desejo de se associarem, conforme a lei de 22 de março de 1890, para execução de medidas sanitárias, elas poderão adotar os mesmos regulamentos que lhes serão tornados aplicáveis segundo os termos aprovados pela dita lei.

Art. 3. Em caso de urgência, quer dizer, em caso de epidemia ou de um outro perigo iminente para a saúde pública, o prefeito pode ordenar a execução imediata, reservar todos os direitos, de medidas prescritas pelos regulamentos sanitários previstos pelo artigo $1^{\circ}$. A urgência deve ser constada por um decreto do prefeito e, em sua ausência, por um decreto do subprefeito, quer esse decreto se aplica a uma ou várias pessoas, quer ele se aplique a todos os habitantes da comuna.

Art. 4. A lista das doenças às quais são aplicáveis as disposições da presente lei será apresentada nos próximos seis meses que se seguirão à promulgação, por um decreto do Presidente da República, junto do relatório do Ministro do Interior, após anuência da Academia de Medicina e do Comitê consultivo de higiene pública de França. Ela poderá ser revisada da mesma forma.

Art. 5. A declaração de autoridade pública de todo caso de uma das doenças objetivadas no artigo 4 é obrigatória para todo médico, oficial de saúde ou parteira, quando constatada a sua existência. Um decreto do Ministro do Interior, após anuência da Academia

\footnotetext{
${ }^{5}$ Para fins de compreensão, optamos por traduzir Maire por prefeito, e préfet por subprefeito, para manter a hierarquia existente naquela sociedade, tendo em vista que essa divisão administrativa não tem equivalência no Brasil. Tradução de Gisele Sanglard, revisão de Renato da Gama-Rosa.
} 
de Medicina e do Comitê consultivo de higiene pública de França, define o modelo da declaração.

Art. 6. A vacinação antivariólica é obrigatória no decorrer do primeiro ano de vida, assim como a revacinação no decorrer do $11^{\circ}$ e $21^{\circ}$ Aniversário. Os pais ou tutores são conclamados pessoalmente à execução da dita medida. Um regulamento da administração pública, após anuência da Academia de Medicina e do Comitê consultivo de higiene pública de França, fixará as medidas necessárias para a aplicação do presente artigo.

Art. 7 A desinfecção é obrigatória para todos os casos de doenças previstas no artigo 4; os processos de desinfecção deverão ser aprovados pelo Ministro do Interior, após anuência do Comitê consultivo de higiene pública de França. As medidas de desinfecção são executáveis nas cidades de 20.000 ou mais habitantes, pelos cuidados da autoridade municipal, a partir dos decretos do prefeito, aprovados pelo subprefeito e, nas comunas de menos de 20.000 habitantes, pelos cuidados de um serviço departamental. As disposições da lei de 21 de julho de 1856 e dos decretos e determinações posteriores, tomadas conformemente às disposições da dita lei, são aplicáveis aos aparelhos de desinfecção. Um regulamento da administração pública, após anuência do Comitê consultivo de higiene pública de França, determinará as condições nas quais esses aparelhos devem ter do ponto de vista da eficácia das operações a serem efetuadas.

Art. 8. Quando uma epidemia ameaça todo ou uma parte do território da República ou aí se desenvolve, e que os meios de defesa locais são reconhecidamente insuficientes, um decreto do Presidente da República determina, após anuência do Comitê consultivo de higiene pública de França, as medidas próprias para impedir a propagação dessa epidemia. Ele regula as atribuições, a composição e a saída das autoridades e administrações encarregadas da execução das medidas, lhes delega, por um tempo determinado, $\mathrm{o}$ poder de executá-las. As tarifas de execução das medidas, de pessoal e de material, estão a cargo do Estado. Os decretos e os atos administrativos que antecedem a aplicação das medidas são executáveis nas 24 horas, a partir da publicação no Diário Oficial.

Art. 9. Quando ao longo de três anos consecutivos o numero de óbitos em uma comuna tenha ultrapassado a cifra da metade da média da França, o prefeito é obrigado a encarregar o conselho departamental de higiene de proceder, seja por si próprio, seja pela comissão sanitária da circunscrição, a uma enquête sobre as condições sanitárias da comuna. Se essa pesquisa estabelece que o estado sanitário da comuna necessita de trabalhos de saneamento, notadamente das águas servidas estagnadas, o prefeito, depois de uma conclamação à comunidade onde não tenha surtido efeito, convida o conselho departamental de higiene a deliberar sobre a utilidade e a natureza dos trabalhos que se fazem necessários. O prefeito é incitado a apresentar as observações ante o conselho departamental de higiene. Em caso de opinião contrária à execução de obras por parte do conselho departamental de higiene ou de reclamação da comuna, o prefeito transmite a deliberação do conselho ao Ministro do interior, que se ele julgar necessário, submete a questão ao Comitê consultivo de higiene pública da França. Esse procede a uma pesquisa cujos resultados são afixados na comuna. Sobre a opinião do conselho departamental de higiene e do Comitê consultivo de higiene pública da França, o prefeito incita a comuna a desenvolver o projeto e a iniciar os trabalhos. Se no mês que sucede ao início das discussões, o conselho municipal ainda não tiver se pronunciado a favor, ou se no três meses seguintes ele não tiver tomado nenhuma medida visando a execução dos trabalhos, um decreto do Presidente da República, enviado ao Conselho de Estado, ordena 
esses trabalhos, cuja execução é determinada por ele. A despesa só poderá ser atribuída à comuna pela força de uma lei. O conselho geral define, nas condições previstas pelo artigo 40 da lei de 10 de agosto de 1871, a participação do departamento nas despesas dos trabalhos aqui especificados.

Art. 10. O decreto que declara como de utilidade pública a captação de uma fonte para o abastecimento de uma comuna determinará ao mesmo tempo, se couber, os terrenos que se deve adquirir propriedade plena, bem como um perímetro de segurança contra a poluição da dita fonte. É proibido a edificação nos terrenos compreendidos nesse perímetro, de lavouras e de perfuração de poços sem autorização do prefeito. A indenização devida ao proprietário desses terrenos será determinada segundo as formas da lei de 3 de maio de 1841 que versa sobre a expropriação de terrenos para utilidade pública, tanto quanto para as heranças de pleno direito. Essas disposições, são aplicadas aos poços ou às galerias fornecedoras de água potável advinda de um lençol freático. O direito ao uso de uma fonte de água potável implica, à comuna que a possui, o direito de cuidar dessa fonte, de cobri-la e de garanti-la contra todas as causas de poluição, mas não o de desviar seu curso através de dutos e canais. Um regulamento da administração pública determinará, se couber, as condições nas quais o direito de uso poderá ser exercido. A aquisição do todo ou da parte de uma fonte de água potável para a comuna na qual ela está situada pode ser declarada de utilidade pública por decreto da prefeitura, quando a quantidade a ser adquirida não ultrapassar dois litros por segundo. Esse decreto é editado por demanda do conselho municipal e com anuência do conselho de higiene do departamento. Ele deve ser precedido de uma pesquisa prevista pela ordenação de 23 de agosto de 1835. A indenização de exploração é regulamentada na forma prescrita pelo artigo 10 da lei de 21 de [maio] de 1836.

\section{CAPÍTULO II - Medidas sanitárias relativas aos imóveis.}

Art. 11. Nas aglomerações de 20.000 habitantes e acima, nenhuma habitação pode ser construída sem uma permissão do prefeito constando que, no projeto que lhe foi submetido, as condições de salubridade prescrita por regulamento sanitário, previsto no artigo

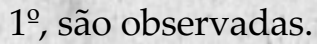

Independente do prefeito instaurar no limite de 20 dias, contado a partir da entrada na prefeitura do pedido de construir quando será considerado recebido, o proprietário poderá se considerar como autorizado a começar seus trabalhos. A autorização de construir pode ser dada pelo subprefeito em caso de negativa do pre-feito. Se a autorização não tiver sido pedida ou se as prescrições do regulamento sanitário não tiverem sido observadas, será instruído um processo. Em caso de não execução das prescrições, é procedido conforme as disposições do artigo seguinte.

Art. 12. Quando o imóvel, construído ou não, dando ou não para a via pública, é perigoso para a saúde dos ocupantes ou vizinhos, o prefeito ou, em sua ausência, o subprefeito, convida a comissão sanitária prevista no artigo 20 da presente lei a se pronunciar: 1 ) sobre a utilidade e a natureza dos trabalhos; 2 ) sobre a interdição de habitação do todo ou de parte do imóvel até que as condições de insalubridade tenham desapa- 
recido. O relatório do prefeito coloca à disposição dos interessados o secretariado da prefeitura. Os proprietários, aqueles que detêm usufruto, ou os usuários dos imóveis, são avisados, com pelo menos 15 dias de antecedência, pela diligência do prefeito e por carta com aviso de recepção, da reunião da comissão sanitária, ocasião em que poderão produzir suas observações. Eles devem, se fizerem o pedido, ser ouvidos pela comissão, pessoalmente ou por representante, e poderão serão chamados às visitas e para vistoria. Em caso de opinião contrária às proposições do prefeito, esta é transmitida ao subprefeito, que conclama, se houver necessidade, o conselho departamental de higiene. O prefeito avisa aos interessados, com pelo menos 15 dias de antecedência, por carta com aviso de recebimento da reunião do conselho departamental de higiene e os convida a produzir suas observações nesse período. Eles podem pedir para verem as considerações da comissão sanitária, depositada na prefeitura, e se apresentar, pessoalmente ou por procurador, perante o conselho; eles são chamados nas visitas e nas vistorias. A opinião da comissão sanitária ou do conselho de higiene determina o prazo no qual os trabalhos devem ser executados ou no qual o imóvel deve ser habitado na totalidade ou em parte. Esse tempo só começa a contar a partir da expiação do prazo de recurso aberto aos interessados pelo artigo 13 seguinte ou da notificação da decisão definitiva proposta nos recursos. No caso em que a da comissão não tiver sido contestada pelo prefeito ou se não tiver sido contestado de forma alguma, após a notificação pelo prefeito da anuência do conselho departamental de higiene, o prefeito determina os trabalhos necessários ou anuncia a interdição do local, e responsabiliza o proprietário e o incita a agir no prazo fixado. O mandato de interdição de habitação deve ter a aprovação do prefeito.

Art. 13. Um recurso é oferecido aos interessados contra o mandato do prefeito ante ao Conselho da prefeitura, no prazo de um mês a contar da notificação do decreto. O recurso é suspensivo.

Art. 14 A despeito do recurso contra o mandato do prefeito ou si o mandato foi mantido, os interessados que não tiverem executado, no prazo fixado, os trabalhos julgados necessários, são intimados no tribunal de polícia, que autoriza o prefeito a executar os trabalhos necessários, às custas dos proprietários, sem prejuízo da aplicação do artigo 471, §15, do Código Penal. Em caso de interdição da habitação, se o trabalho não tiver sido feito a contento, os interessados são passíveis de uma multa de 10 francos a 500 francos e intimados ao Tribunal Correcional, que autoriza o prefeito a expulsar, às custas dos interessados, os ocupantes do imóvel.

Art. 15. A despesa resultante da execução dos trabalhos é garantida por um privilégio sobre os rendimentos do imóvel, que se torna conceito público após os privilégios enunciados nos artigos 2101 e 2103 do Código Civil.

Art. 16. Todas as intervenções praticadas para a execução das medidas de saneamento prescritas em virtude da presente lei, são isentas de contribuição das portas e janelas durante cinco anos consecutivos, a partir da finalização dos trabalhos.

Art. 17. Quando, em seguida à execução da presente lei, for preciso a execução de vigas de sustentação, essa realização não trará, aos locatários, nenhum estrago ou juros.

Art. 18. Quando a insalubridade é resultado das causas exteriores e permanentes, ou quando as causas de insalubridade só podem ser sanadas por trabalhos do conjunto, a comuna pode obter, segunda as formas e após cumpridas as formalidades prescritas pela lei de 3 de maio de 1841, a totalidade das propriedades compreendidas no perímetro dos trabalhos. As porções dessas propriedades que, após saneadas, ficarem fora dos alinha- 
mentos propostos pelas novas construções, poderão ser revendidas em leilões públicos, sem que seus antigos proprietários ou seus herdeiros diretos possam pedir a aplicação dos artigos 60 e 61 da lei de 3 de maio de 1841, se tais partes que sobrarem não sejam extensão da propriedade original ou se constituam uma forma que permita elevar em seu lugar uma construção salubre.

\section{TÍTULO II - DA ADMINISTRAÇÃO SANITÁRIA}

Art. 19. Se o prefeito, para assegurar a execução da presente lei, estima que pode ser organizado um serviço de controle e inspeção, ele só poderá proceder após uma deliberação do conselho geral regulamentando os detalhes e o orçamento do serviço. Nas cidades de 20.000 ou mais habitantes, e nas comunas de menos de 2.000 habitantes, que tenham um estabelecimento termal, será instaurado, com o nome de bureau de higiene, um serviço municipal encarregado, sob autoridade do prefeito, da aplicação das disposições da presente lei.

Art. 20. Em cada departamento, o conselho geral, após anuência do conselho de higiene departamental, delibera, nas condições previstas para o artigo 48, §5, da lei de 10 de agosto de 1871, sobre a organização do serviço de higiene pública no departamento, notadamente sobre a divisão do departamento em circunscrições sanitárias, providas, cada uma, de uma comissão sanitária, sobre a composição, o modo de funcionamento, a publicação dos trabalhos e as despesas do conselho departamental e das comissões sanitárias. A despeito do conselho geral instaurar tal conselho, este será estabelecido por um decreto em forma de regulamento de administração pública. O conselho de higiene departamental será composto de no mínimo dez e no máximo de quinze membros. Compreenderá necessariamente de dois conselhos gerais, eleitos por seus pares, três médicos, sendo um do exército ou da marinha, um farmacêutico, o engenheiro-chefe, um arquiteto e um veterinário. O prefeito presidirá o conselho, que nomeará, no seu interior, para um mandato de dois anos um vice-presidente e um secretário, encarregado de redigir as deliberações do conselho. Cada comissão sanitária de circunscrição será composta de no mínimo cinco e no máximo sete membros, pertencentes à circunscrição, eleitos por seus pares, sendo um médico, um arquiteto ou outro homem de artes, e um veterinário. $\mathrm{O}$ subprefeito presidirá a comissão, que nomeará no seu interior, para um mandato de dois anos, um vice-presidente e um secretário encarregado de redigir as deliberações da comissão. Os membros dos conselhos de higiene, à exceção dos conselheiros gerais que são eleitos pelos pares, são nomeados pelo perfeito por um período de quatro anos e confirmados a cada dois anos; os membros podem ser reconduzidos ao cargo. Os conselhos departamentais de higiene e as comissões sanitárias não podem deliberar sobre os assuntos que lhes são submetidos nos casos previstos pela presente lei, se não houver ao menos dois terços de seus membros presentes. Eles podem recorrer a todas as medidas de instrução que se julguem necessárias.

Art. 21. Os conselhos de higiene departamentais e as comissões sanitárias devem ser consultadas sobre os objetos enumerados no artigo 9 do decreto de 18 de dezembro de 1848, acerca do abastecimento de água potável nas aglomerações, acerca da estatística demográfica e a geografia médica, sobre os regulamentos sanitários comunais e genericamente sobre todas as questões interessantes de saúde pública, no limite de suas circunscrições. 
Art. 22. O prefeito do Senna tem, dentre suas atribuições, em Paris, tudo relativo à salubridade das habitações e de suas dependências, seja aquela dos alojamentos em mansardas, a salubridade das vias privadas fechadas ou não em suas extremidades, a captação e a distribuição de água, o serviço de desinfecção, de vacinação e do transporte dos doentes. Para a desinfecção e o transporte dos doentes, dará segmento, nos casos fracassados, às demandas que lhe serão encaminhadas pelo prefeito de polícia. Nomeará uma comissão de alojamento insalubre, composta por trinta membros, dentre os quais quinze sobre a designação do conselho municipal de Paris. Para medidas transitórias, a cada renovação do terço da comissão que funciona atualmente, o prefeito nomeia dez membros, sendo cinco designados pelo conselho municipal.

Art. 23. O prefeito de polícia tem entre suas atribuições:

As precauções para prevenir ou cessar as doenças transmissíveis objeto do artigo 4 dessa lei, especialmente a recepção das declarações; as convenções relativas à obrigação da vacinação e da revacinação; a fiscalização do ponto de vista sanitário dos alojamentos alugados nas mansardas.

Ele continuará a assegurar a proteção das crianças na primeira idade, a vigilância sanitária dos animais; a vigilância do exercício da medicina e da farmácia; a aplicação de leis e regulamentos concernentes à venda e a colocação à venda de mercadorias para consumo alimentar falsificadas ou estragadas, o funcionamento do laboratório municipal de química, a regulamentação dos estabelecimentos classificados como perigosos, insalubres ou incômodos, tanto em Paris como nas comunas sob jurisdição da prefeitura de polícia.

O prefeito de polícia será assistido pelo conselho de higiene e salubridade do Sena, cuja composição será mantida, a saber:

$\S$ O prefeito de polícia, presidente;

$\S$ Um vice-presidente e um secretário, nomeados anualmente pelo prefeito de polícia sobre a representação do conselho de higiene;

$\S$ Vinte e quatro membros titulares nomeados pelo Ministro do Interior, baseado na proposição do prefeito de polícia e da representação do conselho de higiene;

$\S$ Três membros do conselho geral do Sena, eleitos por seus pares;

$\S$ Quinze membros em razão de suas funções: o decano da faculdade de medicina, o professor de higiene da faculdade de medicina, o professor de medicina legal da faculdade de medicina, o diretor da escola superior de Farmácia de Paris, o presidente do comitê técnico de saúde das força armadas, o diretor do serviço de saúde da circunscrição militar de Paris, o engenheiro-chefe de águas e saneamento, o inspetor geral de saneamento e habitação, o secretário-geral da prefeitura de polícia, o engenheiro-chefe das minas encarre-gado do serviço de vapor do Sena, o engenheiro chefe de ponts et chaussées encarregado do serviço ordinário do departamento, o chefe da segunda divisão da prefeitura de polícia, o arquiteto chefe da prefeitura de polícia, o chefe do serviço veterinário do Sena e o chefe do bureau de higiene da prefeitura de polícia.

O conselho de higiene e de salubridade do Sena exercerá as atribuições dadas ao conselho departamental de higiene pela presente lei, na área de atuação da prefeitura de polícia. 
As comissões de higiene, instituídas em Paris e na área de atuação da prefeitura de polícia continuarão a exercer suas funções sob autoridade do prefeito de polícia nas condições indicadas pelos decretos de 16 de dezembro de 1851, 7 de julho de 1880 e 20 de dezembro de 1893 e elas terão suas atribuições dadas às comissões sanitárias das circunscrições pela presente lei.

O prefeito de polícia continuará a aplicar nas comunas pertencentes à sua jurisdição, as atribuições de polícia sanitária das quais está investido atualmente.

Art. 24. Nas comunas do departamento do Sena, que não Paris, o prefeito exerce as atribuições sanitárias inerentes ao prefeito de polícia do Sena, quais sejam as do prefeito de polícia segundo as distinções feitas nos dois artigos precedentes.

Art. 25. O comitê consultivo de higiene pública delibera sobre todas as questões relativas à higiene pública, ao exercício da medicina e da farmácia, as condições de exploração e venda de água mineral, sobre as quais o comitê é consultado pelo Governo.

É necessário consultar sobre os trabalhos públicos de saneamento ou de abastecimento de água das cidades de mais de 5.000 habitantes e sobre a classificação dos estabelecimentos insalubres, perigosos ou incômodos.

É especialmente encarregado do controle da fiscalização da captação das águas fora dos limites de seu departamento, para abastecimento das cidades.

O Comitê consultivo de higiene pública da França é composto por quarenta e cinco membros.

São membros de direito o diretor da assistência e de higiene públicas do Ministério do interior; o inspetor geral dos serviços sanitários; o inspetor geral adjunto dos serviços sanitários; o arquiteto inspetor dos serviços sanitários; o diretor de administração departamental e comunal do Ministério do interior; o diretor dos consulados e assuntos comerciais do Ministério dos Assuntos estrangeiros; o diretor geral das alfândegas; o diretor das estradas de ferro do Ministério das Obras públicas; o diretor do trabalho do Ministério do Comércio, dos Correios e Telégrafos; de ensino primário do Ministério da Instrução pública; o presidente do comitê técnico da saúde das forças armadas; o diretor do serviço de saúde do exército; o presidente do conselho superior de saúde da marinha; o presidente do conselho Superior de saúde do Ministério das Colônias; o diretor dos domínios do Ministério das Finanças; o decano da faculdade de medicina de Paris; o diretor da escola de farmácia de Paris; o presidente da câmara de comércio de Paris; o diretor de administração geral da assistência pública de Paris; o vice-presidente do conselho de higiene e de salubridade do departamento do Sena; o inspetor geral do serviço de saneamento das habitações da prefeitura do Sena; o vice-presidente do conselho de fiscalização da assistência pública de Paris; o inspetor geral as escolas veterinárias; o diretor da carta geológica da França.

Seis membros serão nomeados pelo Ministro a partir de uma lista tríplice de apresentação feita pela Academia de Ciências, Academia de Medicina, Conselho de Estado, Corte de Cassação, Conselho superior do trabalho, Conselho de assistência pública da França.

Quinze membros serão designados pelo Ministro entre médicos, higienistas, engenheiros, químicos, legistas, etc.

Um decreto da administração pública regulamentará o funcionamento do Comitê consultivo de higiene pública da França, a nomeação dos auditores e a constituição de uma sessão permanente. 


\section{TÍTULO III - DESPESAS}

Art. 26. As despesas que se fizerem necessárias pela presente lei, notadamente aquelas causadas pela destruição de mobiliário, são obrigatórias. Em caso de contestação de sua necessidade, será definido por decreto do Conselho de Estado. Estas despesas serão repartidas entre as comunas, departamentos e o Estado, segundo as regras fixadas nos artigos 27, 28 e 29 da lei de 15 de julho de 1893 (completada L. 22 de junho de 1906). Todavia, as despesas de organização do serviço de desinfecção nas cidades de 20.000 ou mais habitantes, são assumidas pelas cidades e pelo Estado, nas proporções estabelecidas na tabela $\mathrm{A}$, anexada à lei de 15 de julho de 1893. As despesas de organização do serviço departamental de desinfecção são assumidas pelos departamentos e pelo Estado, nas proporções estabelecidas na tabela B. - Taxas serão estabelecidas por um regulamento da administração pública por reembolso das despesas relativas a esse serviço. A despeito das cidades e departamentos organizarem seus serviços de desinfecção e os bureaux de higiene e de assegurar o funcionamento deles pela presente lei, será provido por decretos na forma de regulamentos da administração pública.

\section{TíTULO IV - PENALIDADES}

Art. 27. Será punido com penas descritas no artigo 471 do Código penal qualquer um, a exceção dos casos previstos pelo artigo 21 da lei de 30 de novembro de 1892, que tenha cometido uma contravenção às prescrições dos regulamentos sanitários previstos nos artigos 1 e 2, assim como os artigos 5, 6, 7, 8 e 14. Aquele que tiver construído uma habitação sem a permissão do prefeito receberá uma multa entre 16 e 500 francos.

Art. 28. Qualquer um que, por negligência ou desleixo, degradar bens públicos ou comunais destinados a receber ou a conduzir águas para abastecimento; qualquer um que, por negligência ou desleixo, deixar vazar excrementos, ou toda matéria suscetível de contaminar a salubridade, as águas das fontes, chafarizes, poços, cisternas, canalização, aquedutos, reservatórios de água destinados ao abastecimento público, será punido com penas descritas nos artigos 479 e 480 do Código Penal. É proibido, sob as mesmas penas, o abandono de cadáveres de animais, restos de açougue, fumeiro, matérias fecais e, em geral, de resíduos animais passíveis de putrefação nas fendas, nos abismos, fossas ou escavações de qualquer outra natureza que não as fossas necessárias ao funcionamento dos estabelecimentos classificados. Todo ato voluntário da mesma natureza será punido sob as penas descritas no artigo 257 do Código Penal.

Art. 29. Serão punidos com uma multa de 100 a 500 francos e, em caso de reincidência, de 500 a 1000 francos, todos aqueles que obstaculizarem as ações dos prefeitos e membros delegados das comissões delegadas sanitárias, que envolvem a aplicação da presente lei.

Art. 30. O artigo 403 do Código penal é aplicável em todos os casos previstos pela presente lei. É igualmente aplicável às infrações punidas correcionais pela lei de 3 de março de 1822.

\section{TÍTULO V - DISPOSIÇÕES DIVERSAS}

Art. 31. A lei de 13 de abril de 1850 é anulada, assim como todas as disposições e leis anteriores contrárias a presente lei. Os conselhos departamentais de higiene e os conse- 
lhos de higiene dos bairros atualmente existentes continuarão a funcionar até sua substituição pelos conselhos departamentais de higiene e até as comissões sanitárias de circunscrição organizadas executarem a presente lei.

Art. 32. A presente lei não é aplicável às oficinas e às manufaturas.

Art. 33. Os regulamentos de administração pública determinarão as condições de organização e de funcionamento dos bureaux de higiene e do serviço de desinfecção, assim como as condições de aplicação da presente lei na Argélia e nas colônias da Martinica, Guadalupe e Reunião.

Art. 34. A presente lei só será executada um ano após sua promulgação. 


\section{REFERÊNCIAS BIBLIOGRÁFICAS}

Benchimol, Jaime

Larry (coord.)

2001

Bourdelais,

Patrice (dir.)

2001

Chalhoub, Sidney 2004

Gaudin, Jean-Pierre 1985

Faure, Olivier 1993

Faure, Olivier 1994

Horne, Janet 2004

Barbosa, Plácido;

Rezende, Cássio

Barbosa de 1909
Febre Amarela - a doença e a vacina, uma história inacabada.

Rio de Janeiro: Bio-Manguinhos/Ed. Fiocruz.

Les higiénistes, enjeux, modèles et pratiques (XVIIIe - XXe Siècles).

Paris: Belin.

Cidade Febril - cortiços e epidemias na corte imperial. São Paulo: Companhia das Letras.

L'avenir en plan. Technique et politique dans la prévison urbaine. 1900-1930. s.l.: Éd. du Champ Vallon.

Les Français et leur médecine aux XIXè siècle.

Paris: Belin.

Histoire sociale de la médecine (XVIIIè - XXè Siècles).

Paris: Anthropos Histhoriques.

Le Musée Social.

Aux origines de l'État providence. Paris: Belin.

Os serviços de Saúde Pública no Brasil: especialmente na cidade do Rio de Janeiro de 1808 a 1907 - esboço histórico e legislação.

Rio de Janeiro: Imprensa Nacional.

Recebido para publicação em janeiro de 2005.

Aprovado para publicação em maio de 2005. 